\title{
Methods and Techniques of Electricity Thieving in Pakistan
}

\section{Zahoor Hussain*, Shahzad Memon, Razahussain Shah, Zulfiqar Ali Bhutto, Mahmoud Aljawarneh}

Institute of Information and Communication Technology, University of Sindh, Jamshoro, Pakistan

Email: *zahoorshah@scholars.usindh.edu.pk, shahzad.memon@usindh.edu.pk,raza.shah@usindh.edu.pk, zulfiqarali.bhutto@usindh.edu.pk, maljawarneh@scholars.usindh.edu.pk

How to cite this paper: Hussain, Z., Memon, S., Shah, R., Bhutto, Z.A. and Aljawarneh, M. (2016) Methods and Techniques of Electricity Thieving in Pakistan. Journal of Power and Energy Engineering, 4, 1-10.

http://dx.doi.org/10.4236/jpee.2016.49001

Received: November 11, 2015

Accepted: September 2, 2016

Published: September 5, 2016

Copyright $\odot 2016$ by authors and Scientific Research Publishing Inc. This work is licensed under the Creative Commons Attribution International License (CC BY 4.0).

http://creativecommons.org/licenses/by/4.0/

\begin{abstract}
The situation of electricity in Pakistan has been alarming from the last ten years. The deficiency in electricity has not only obstructed the business activities but also affected the domestic consumers, educational institutes and hospitals. Usually electrical power companies are liable for electricity shortfall and power interruption. However, electricity end consumers are also equally responsible behind strange shortfall and unusual power interruption. Frequently, the consumers use the heavy electrical equipment in their homes including heaters, geysers, irons and water motors which causes the more electricity consumption, load shedding and huge amount of bills. For escaping the huge amount of electricity bill, the consumers commit the illegal and unethical connections. The illegal usage of electrical power failed the power companies to plan schedule load shedding accordingly and the other side the damaged electricity wires or Pole Mount Transformer increased faults due to overburdening, which directly affected on extend power interruption. In addition that, responsible teams of electrical power companies cannot reach instantly to repair faults and prevent the theft. Electricity thieving is social crime committed by the consumers or meter readers which causes the electricity strange shortfall within country. This paper presents the practical demonstration about the common energy theft methods and techniques done by electricity consumers within their home and residential building. In Pakistan EPC (electrical power companies) deploy the traditional electromechanical meters for electricity consumption measurements, however, these meters do not have any real time communication. Therefore there are many easy ways to manipulate the meter reading as well as internal structural of metering system.
\end{abstract}

\section{Keywords}

Electromechanical Meter, Technical and Non-Technical Losses, Electrical Panel Board, Electrical Power Distribution Mechanism, Power Losses, Method and Techniques 


\section{Introduction}

Energy theft can be in the form of deception such as meter tampering, illegal connections (bypassing meter connections), physical destruction of energy meters, stop the rotated disk of energy meters and fake billing. Energy theft cases are occurred in the most regions of the world. Approximately 102 countries including Pakistan faced the electricity theft concern due to poor infrastructure, political uncertainty, highly level corruption, low level government efficiency, appointments of non-technical staff, and deficiency of accountability, law and order situations [1]. Pakistan is the country where all natural resources are available for the generation of electricity, but unfortunately there is lack of long term planning for the generation of electricity and theft detection. The economy loss is Rs 90 billion per year due to theft of electrical power at commercial, domestic and industrial level. According to the report of Northeast Group [2] it reported 89.3 billion US dollar losses have been occurred during the year 2015 in all over the world. India is the country where the losses are $\$ 16.2$ billion from its income due to the electricity theft, Brazil $\$ 10.5$ Billion, Russia $\$ 5.1$ billion and Pakistan $\$ 0.89$ respectively. Figure 1 summarized the country's economy losses due to theft. There are two types of losses TL (technical losses) and NTL (non-technical losses) during the transmission of electricity. These are major issues in under developing countries and it has been very difficult task for electricity supply companies to hunt the individuals answerable for electricity stealing. The major electricity theft is occurred in NTL (non-technical losses) area of power sector. NTL are more difficult to measure because these losses are frequently occurred and electric power companies have no any recorded information to control the losses [3]. These losses disturb the supply of electricity, rise power load on grid station and escalation bill imposed on customers. NTL include electricity theft, meter tampering, bill errors, un-meter connection, un-estimated consumer's accounts, false reading by meter readers, and slow the meter reading disk, ignore unpaid customers and metering errors. NTL are usually done by human being who is unaccountable for power companies. TL (Technical losses) are natural losses occurred regularly in power sector and these losses are produced by physical structural properties of power system. TL mainly consist with transmission line,

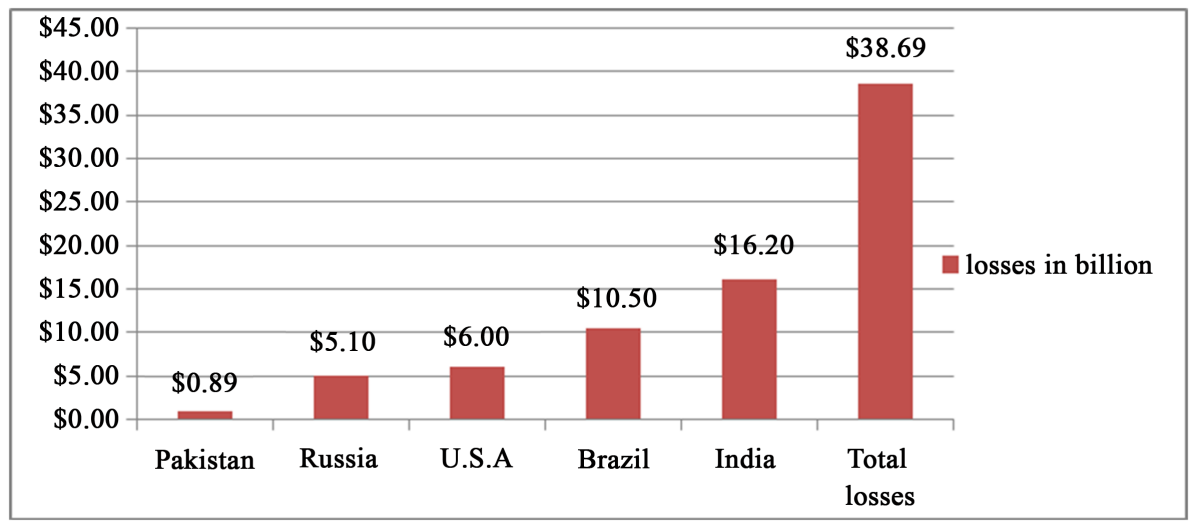

Figure 1. World economies losses billions of dollar per year by electricity theft [2]. 
transformers, substation and electrical network losses [4]. TL losses are occurred due to lengthy single phase lines, improper cable earthling at remote sides, poor power loading, and power over loading on transmission lines, poor quality cable and equipment.

Pakistan is the country where electricity theft is common practices committed by individuals as well as meter readers. The government took serious action to reduce the electricity theft and line losses. There were $18.6 \%$ line losses occurred during the initial months of financial year 2014-2015. According to NEPRA (National Electric and Power Regulatory Authority) $13.5 \%$ line losses are justified average limit. When the electricity losses are more than the $13.5 \%$ justified line losses set by NEPRA, it would be simply reflected as electricity thieving. Justified line losses may be varied on the basis of poor electrical infrastructure of power distribution companies [5]. According the different power distribution companies' line losses are much more than the justified average limit set by NEPRA. Figure 2 comprised the line losses of various power distribution companies in Pakistan.

Such as SEPCO (Sukkur Electric Power Company) has $39.4 \%$ line losses, PESCO (Pakistan Electric Supply Company) 37.4\%, HESCO (Hyderabad Electric Supply Company) 27.6\%, QESCO (Quetta Electric Supply Company) 21.7\%, MEPCO (Multan Electric Power Company ) 19.3\%, LESCO (Lahore Electric Supply Company) 14\%, GEPCO (Gujranwala Electric Power company) 11.1\%, FESCO (Faisalabad Electric Supply Company) $10.8 \%$ and IESCO (Islamabad Electric Supply company) has $6.1 \%$ line losses respectively. The rest of the paper is divided into four sections. The energy theft and losses have been reviewed and discussed in Section 1 and an electrical power distribution mechanism is presented Section 2 demonstrated the various stages of electricity distribution from electrical power generation station to individual home. Common methods and techniques for thieving in Pakistan have been discussed in Section 3. Finally a conclusion is drawn in Section 4.

\section{Electrical Power Distribution Mechanism}

EPC (electrical power companies) transmitted electricity from the EPGS (electrical power generation station) at very high voltage. In Pakistan EPC provide electrical power to various sectors such as commercial, industrial and domestic level. For domestic consumers and small commercial business EPC lower the voltage through different step-down transformer on the electricity power pole mount on the ground. The

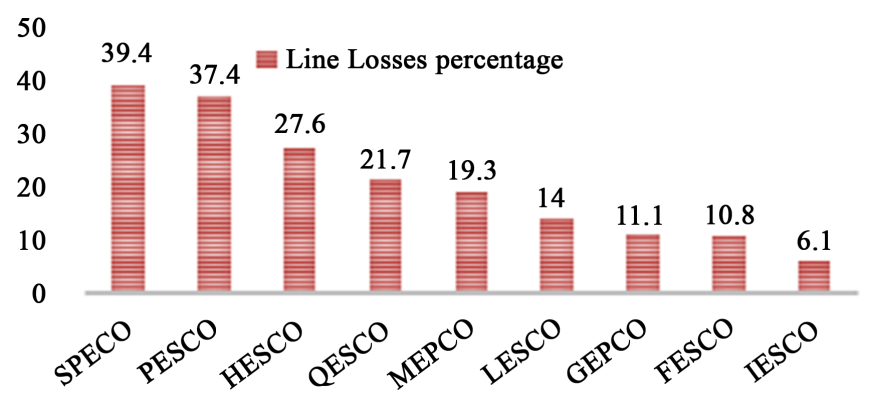

Figure 2. Power line losses in Pakistan [5]. 
EPC will own the transformer, which will mount on the outside of the courtyard and it will be attached with the electricity pole. The step-down transformer reduces the voltage from very high voltage to step-down to $120 / 240$ volts for domestic consumption and then it passes electricity to the meter. After that, the electrical power is distributed through meter inside the building. Meter is electricity owned device which is used to power transmission within building and keep a record of energy consumption. Figure 3 illustrated the electricity distribution network from EPGS to individual home. Though the wire the electrical power in meter is transfer to panel board, it is located within courtyard or outside of the house. The panel board consists with different service circuit and breakers which control the electrical power flow.

\section{Techniques and Methods of Electricity Thieving}

In Pakistan there are many types of methods and techniques for electricity stealing. This paper investigates the various thieving categories used by electricity consumers all over the world and particularly in Pakistan. The electricity thieving methods are divided into two major categories such as meter tempering where imposter manipulate the internal structure of metering system and the another one is line tempering where intruder bypass the electricity meter connection. Theses electricity thieving methods are common and easy to electricity consumers in Pakistan. Therefore the country faced economical losses and the electricity theft concern due to electricity thieving at various levels. Complete content and organizational editing before formatting. Please take note of the following items when proofreading spelling and grammar.

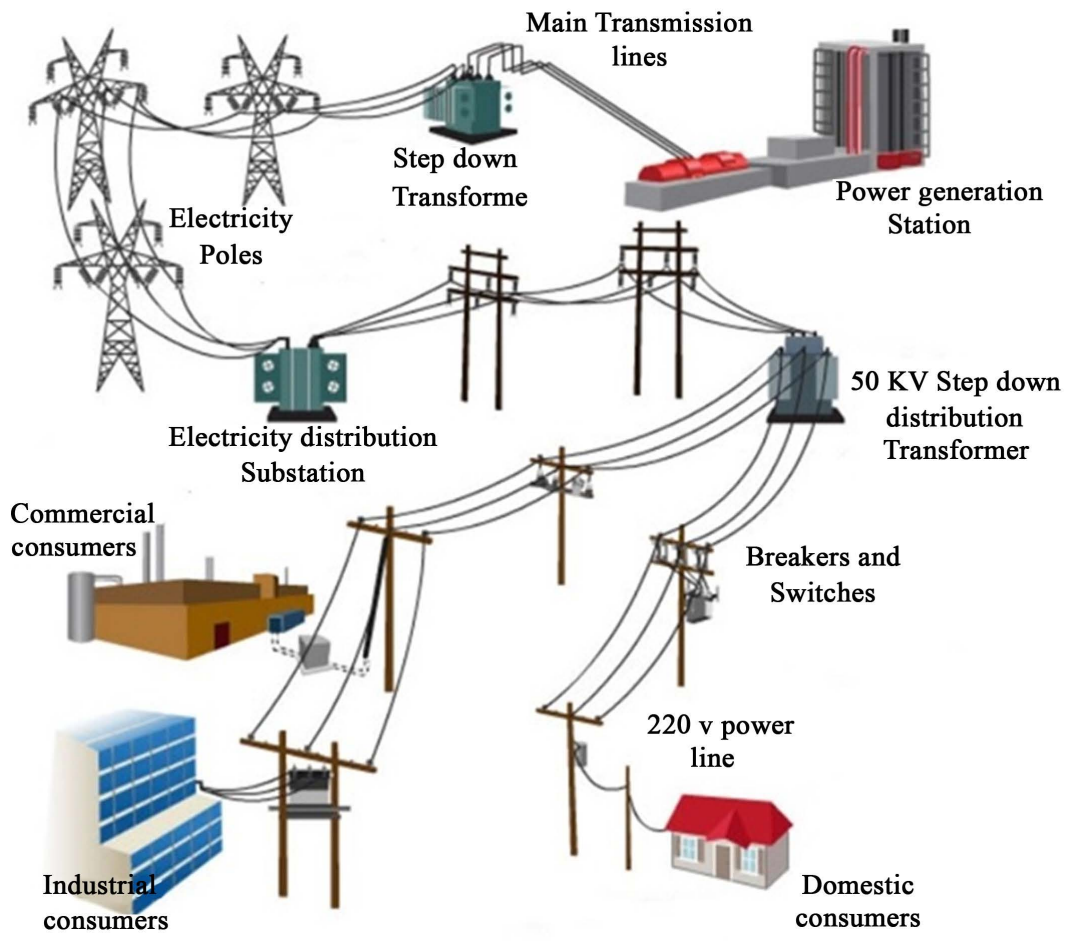

Figure 3. Electricity distribution network. 


\subsection{Bypassing Electricity Meter Connection}

Figure 4 shows the illegal usage of electricity by using the most common method "bypassing electricity meter" connection in different institutes, domestic and industrial level. In this method, the electricity thieves bypass the meter connection inside the home or courtyard. As shown in Figure 3, there is main power line connection from the electrical pole with $220 \mathrm{v}$ (voltages) for the domestic consumers. Usually the main power line is connected with electricity meter for electricity distribution but the thieves bypass this connection and connect the wire before meter panel board. The Result is electricity meter have been bypassed and it will not be able measure the units of electrical power consumption in domestic level.

Result: Electricity meter is bypassed and it couldn't measure the electrical power consumption in home.

\subsection{Direct Hooking (Kunda) from Lines}

Hooking (Kunda) is the most common used method, $80 \%$ of global power theft is by direct tapping from the main power line. The consumer taps into a power line from a point ahead of the energy meter and energy consumption is unmeasured and procured with or without switches. Figure 5 exhibited the direct hooking system from the main power line.

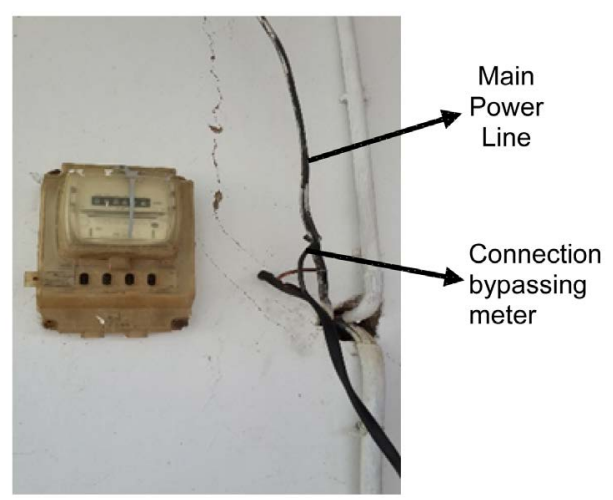

Figure 4. Bypassing meter connection.

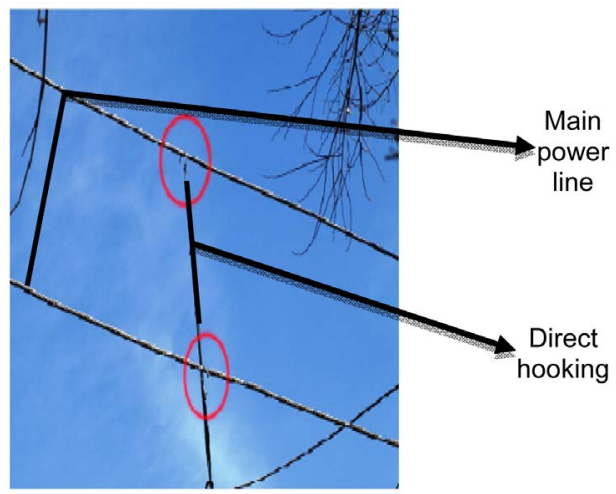

Figure 5. Direct hooking (Kunda) system. 
Result: This energy consumption is unmeasured and procured with or without switches. Figure 5 exhibited the direct hooking system from the main power line.

\subsection{Electricity Panel Board}

We have design an electricity panel and practically demonstrated the possible theft method within electromechanical meters located inside the home. Figure 6(a) and Figure 6(b) presented the electricity panel with electrical power load and without electrical power load respectively.

\subsection{Reverse Meter Counter}

In this theft method the impostors open the meter and reverse the meter counter according to their requirements. After that, they have wrapped meter again and nobody knows about the malpractices with in metering system until the meter is send to laboratory test. The ultimate result is changed meter reading according to their wishes. Figure 7 illustrated the theft technique which is done by impostors internally.

Result: Changed meter reading according to their wishes. Figure 7 illustrated the theft technique which is done by impostors internally.

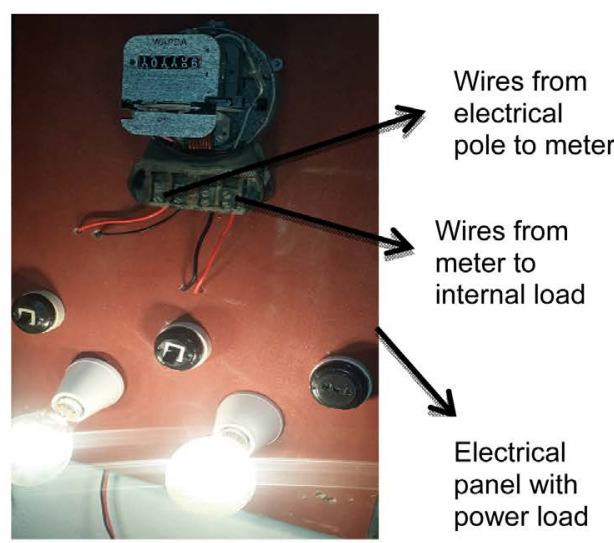

(a)

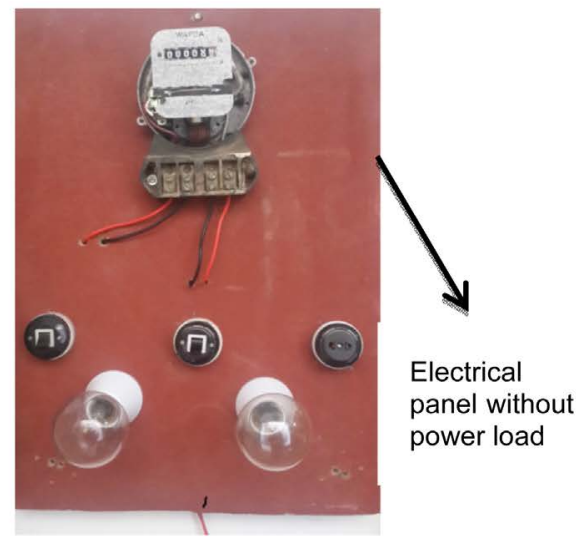

(b)

Figure 6. (a) Electrical panel with power load; (b) Electrical panel without power load.

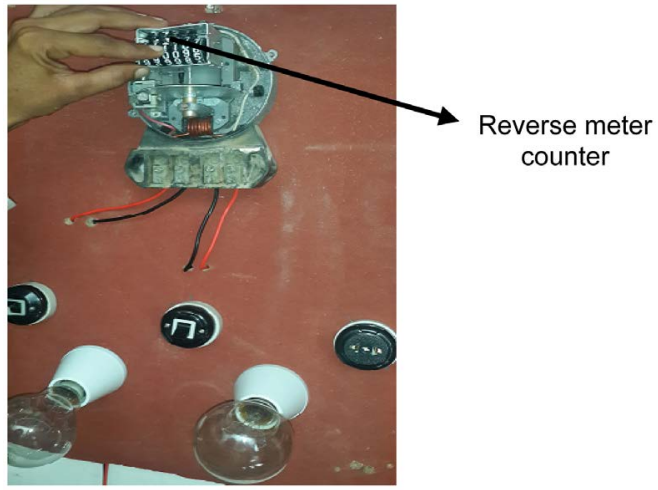

Figure 7. Reverse meter counter. 


\subsection{Use of Magnets}

In this methods the consumers use the magnet material for slow the rotated disk of electromechanical meter. It is also a common method for electricity theft. Figure 8 shows how consumers slow the meter disk. In this common technique the consumers open the electromechanical meter and simply put the magnetic material on the upper surface of rotating disk. It obstructs the free movement of disk and a slower revolving disk signals less electricity consumption.

Result: It obstructs the free movement of disk and a slower revolving disk signals less electricity consumption (see Figure 8).

\subsection{Directional Changes}

The other common techniques is that, change the direction of meter. In this way the rotating disk completely stop its disk movements until meter is relocated to its straight position. Usually meters are installed inside the home in straight position on wall or other suitable place. When the direction of meter changes the rotating disk will be stop automatically. Figure 9(a) presents the actual direction of electricity meter and Figure 9(b) shows the modified direction of electricity meter.

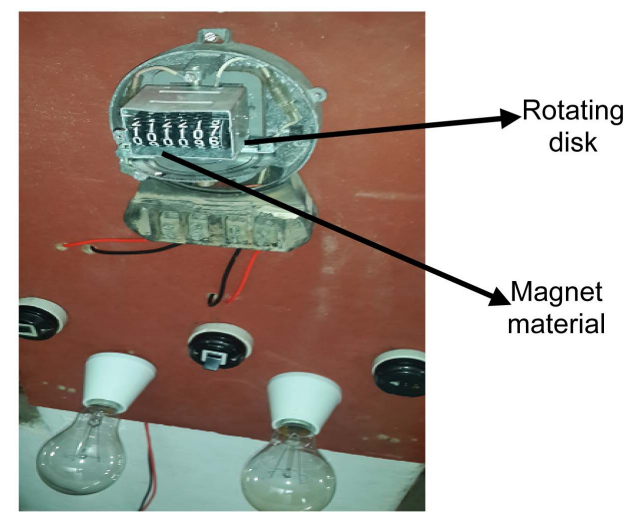

Figure 8. Meter with magnet material.

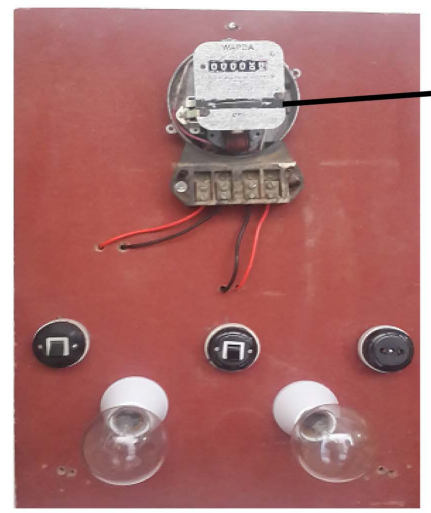

(a)
Straight direction

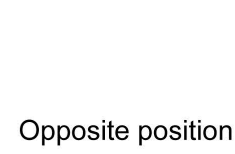

Opposite position

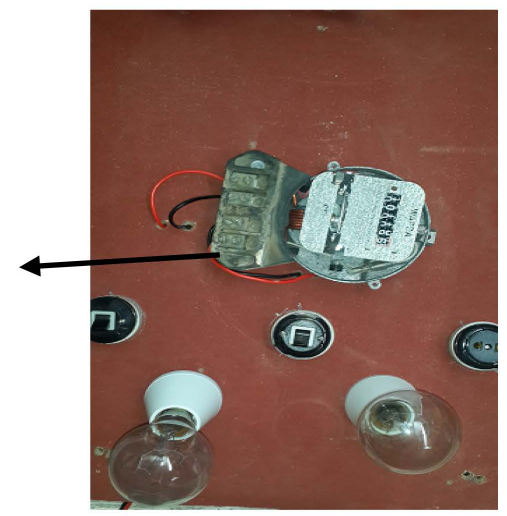

(b)

Figure 9. (a) Straight direction of electricity meter; (b) Opposite direction. 
Result: When the direction of meter should be changed the rotating disk will be stop automatically. Figure 9 presents the straight direction and change direction of electricity meter.

\subsection{Wires Tapping}

It is necessary to connect neutral and power load wires to energy meter in electrical panel board, for electrical load distribution such as red wire indicate the load and black wire indicate the neutral. Figure 8 shows how the consumers or meter reader changed or tapped the neutral wire to stop the meter reading. This is easy method for consumers to commit the malpractice on panel board because it provides easy way for removing and reconnect the neutral wire. In Figure 10(a) consumer removes the neutral wire from the meter hence in Figure 10(b) top surface of neutral wire have been tapped by consumers and in Figure 10(c) the place of wires, both wire places will be swapped to each other. But the neutral wire is not connected to the meter circuit, it is just inserted in other place after tapping, the consumers obtain the neutral earthing from any other place in home. In this technique the electricity is distributed through electromechanical meter panel board but there is no any free movement of rotating meter disk because it needs the connectivity of both (load and neutral) wires.

Result: In this technique electricity is distributed through electromechanical meter panel board but there is no any free movement of rotating meter disk because it needs the connectivity of both (load and neutral) wires.

\subsection{Meter Screw Clinging}

Another easy method of electricity thieving at domestic level is to cling meter screws which hold the rotating disk free movements as its normal level. When there is contention on disk due to screws the speed of rotating disk will be automatically slow. See Figure 11(a) and Figure 11(b). A slower rotating disk signals causes less energy consumption at domestic. It is also a common deception method of electricity.

Result: A slower rotating disk signals causes less energy consumption at domestic level. It is also a common deception method of electricity.

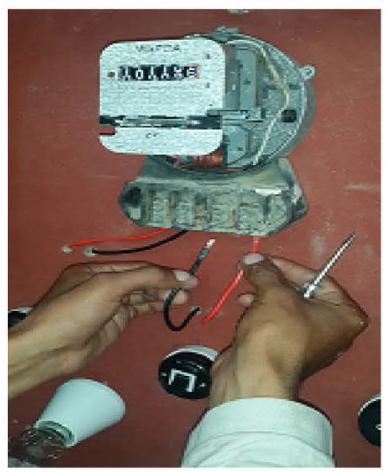

(a)

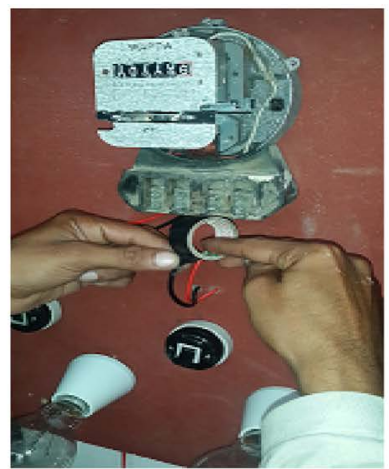

(b)

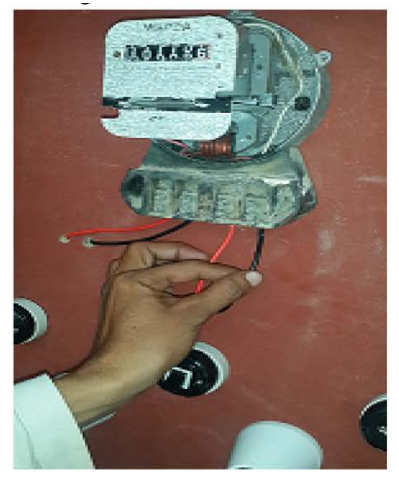

(c)

Figure 10. (a) Remove wire; (b) Tapping wire; (c) Change wire. 


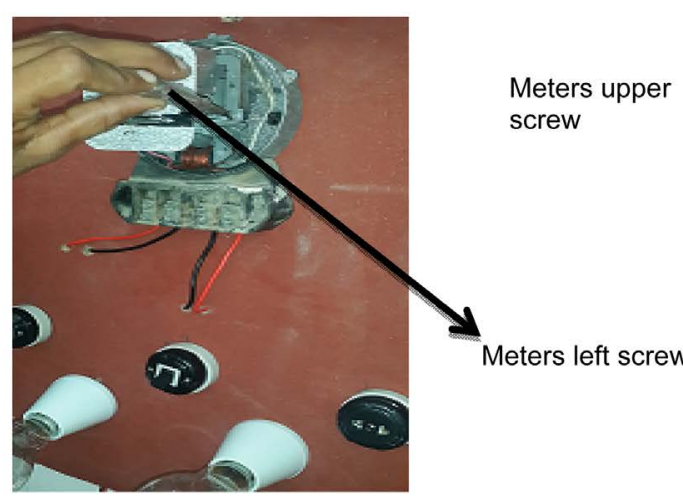

(a)

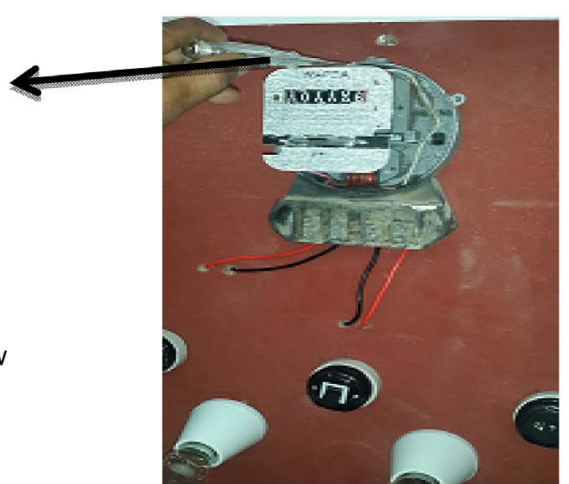

(b)

Figure 11. (a) Press left screw; (b) Press upper screw.

\section{Conclusion}

There are nine government own electrical power distribution companies involved electricity distribution in Pakistan. Since decades electricity industry is under the government supervision and the national regulatory body NEPRA (National Electric Power Regulating Authority) monitoring and determined electricity tariff. It also monitors the performance of electricity distribution companies' performance. NEPRA defines the policy and roadmap for distribution companies, how to control the electricity theft and unpaid bill recovery. However, electricity thieving ratio is more than the previous years because of no punishment for those who have used the illegal electricity connection or tampering the meter, lack of management, law and order situation, corruption, poor infrastructure, poor monitoring system, poor training for staff. Electricity theft is a misconduct and those who associate with illegal connection should be punished. Illegal connection might be valuable for those who have these illegal (kundas) connection but the honest consumers have to abide the burden of huge tariffs and insufficient electrical power supply. The progress and development of economy are dependent on availability of electricity, but Pakistan economy losses more than 89 billion Rupees per year due to electricity theft, irregularities and physical tampering of electricity meters. This paper discusses about the common electricity theft methods and techniques performed by consumers as well as electricity meter readers. These are the easiest way for common consumers and sometime meter reader to thieving electricity. Nobody can identify these thefts until electricity meter is removed and sent for laboratory inspection. Pakis$\tan$ is the country where all theft methods and techniques are carrying out by electricity consumers to save the money illegally.

\section{References}

[1] Smith, T.B. (2004) Electricity Theft: A Comparative Analysis. Energy Policy, 32, 2067-2076. http://dx.doi.org/10.1016/S0301-4215(03)00182-4

[2] (2014) World Loses \$89.3 Billion to Electricity Theft Annually, \$58.7 Billion in Emerging Markets. WASHINGTON, Dec. 9.

http://www.prnewswire.com/news-releases/world-loses-893-billion-to-electricity-theft-ann 
ually-587-billion-in-emerging-markets-300006515.html

[3] Depuru, S.S.S.R., Wang, L. and Devabhaktuni, V. (2011) Electricity Theft: Overview, Issues, Prevention and a Smart Meter Based Approach to Control Theft. Energy Policy, 39, 10071015. http://dx.doi.org/10.1016/j.enpol.2010.11.037

[4] Navani, J.P., Sharma, N.K. and Sapra, S. (2012) Technical and Non-Technical Losses in Power System and Its Economic Consequence in Indian Economy. International Journal of Electronics and Computer Science Engineering, 1, 757-761.

[5] (2015) Electricity Theft Worsens. Accessed: 19 August. http://nation.com.pk/national/30-Jan-2015/electricity-theft-worsens

Submit or recommend next manuscript to SCIRP and we will provide best service for you:

Accepting pre-submission inquiries through Email, Facebook, LinkedIn, Twitter, etc. A wide selection of journals (inclusive of 9 subjects, more than 200 journals)

Providing 24-hour high-quality service

User-friendly online submission system

Fair and swift peer-review system

Efficient typesetting and proofreading procedure

Display of the result of downloads and visits, as well as the number of cited articles Maximum dissemination of your research work

Submit your manuscript at: http://papersubmission.scirp.org/ 